\title{
O ENSINO DA LÍNGUA PORTUGUESA EM TIMOR- LESTE: ÊNFASE NOS GÊNEROS DISCURSIVOS
}

\section{Teaching Portuguese in East Timor: the emphasis on discourse genres}

\author{
Maria Irone Andrade* \\ Angela Di Palma Back** \\ Gladir da Silva Cabral***
}

RESUMO

Este artigo visa a apresentar como ocorre o ensino de língua portuguesa do $12^{\circ}$ ano em uma escola pública do ensino de Dili, Timor-Leste. Mobilizamos para a discussão postulados referentes aos gêneros discursivos, os quais estão correlacionados às atividades de ensino-aprendizagem da língua e possibilitam mudanças nas práticas pedagógicas. As modificações ocorridas nas diretrizes curriculares e no plano curricular do ensino secundário em Timor-Leste propõem aos professores mudança em suas práticas, colocando em perspectiva a aprendizagem da leitura e da produção textual. Entretanto, os resultados desta investigação apontam para o fato de que, embora houvesse mudanças no plano curricular, o professor trabalhava baseado em suas experiências, com poucos conhecimentos no horizonte teórico e muitos questionamentos quanto à aplicação e usos dos gêneros discursivos propostos pelas diretrizes. Em face disso, para melhor compreensão do contexto sócio-histórico de observação dos fatos, faremos breve exposição da expansão da língua portuguesa no Timor-Leste, língua oficial juntamente com o tétum. Fundamentamo-nos em Thomaz (2002) e Albuquerque (2011), quanto ao contexto histórico, social e linguístico, consubstanciados também em referências

* Insituto Insikiran de Formação Superior Indígena (RO).

** Universidade do Extremo Sul Catarinense.

*** Universidade do Extremo Sul Catarinense. 
como Bakhtin (2003), Schneuwly e Dolz (1999) e Marcuschi (2008), cuja orientação se dá na perspectiva interacional da linguagem. Utilizamos observação em sala de aula, diário de campo, entrevistas e questionários com fonte para a coleta e análise de dados, após os quais pudemos depreender que há necessidade de investimento na formação dos professores de língua portuguesa para que possam trabalhar conforme o que é proposto no Plano Curricular de Ensino Secundário de Timor-Leste.

Palavras-chave: língua portuguesa; gêneros discursivos; educação em Timor-Leste; ensino-aprendizagem de língua.

\begin{abstract}
This paper aims at presenting how Portuguese language teaching takes place in high school in Dili, East-Timor. The theoretical background used in the discussion are linked to discourse genres, which are connected to teaching-learning activities and provide for changes in the pedagogical practices. The alterations in the curriculum guides and in the curricular plan for high school in East Timor propose to teachers some changes in their practices, placing in perspective reading and text production learning. However, results point to the fact that, in spite of changes in the curricular level, teachers used to work based on their own experience, having little theoretical knowledge and many doubts about the application and use of the discourse genres proposed by the guides. Thus, in order to better understand the social, historical context, we offer a brief exposition on the Portuguese languages expansion in East Timor, where Portuguese is the official language together with the Tetum. As foundation, we have selected Thomaz (2002) and Albuquerque (2011) in relation to the historical, social, linguistic context, having also as reference authors like Bakhtin (2003), Schneuwly and Dolz (1999), and Marcuschi (2008), who work with language in the interactionist perspective. We have used class room observations, field notes, interviews, and questionnaires as tools for data collection. As a result, we perceive the need of investing in Portuguese language teachers' formation so that they can work according to what is established by the high school curricular plan in East Timor.
\end{abstract}

Keywords: Portuguese; discourse genres; education in Timor-Leste; language teaching-learning. 


\section{INTRODUÇÃo}

Neste artigo, discutimos como se dá, no ensino secundário de uma escola de Dili, o aprendizado da língua portuguesa. Para tanto, buscamos compreender que concepções de ensino-aprendizagem estão postas e de que forma são trabalhadas as práticas de linguagem, visando a apreender se, na prática pedagógica, há ou não um trabalho efetivo segundo a concepção de gêneros discursivos (GD). Nesse contexto, será levado em consideração o fato de que, em Timor-Leste, a língua portuguesa, ao lado da língua tétum, possui o status de língua oficial e de ensino desde 2002, ao passo que 0 inglês e o indonésio são consideradas línguas de trabalho, conforme definido em sua Constituição (TIMOR-LESTE, 2002, p. 12).

A fundamentação teórica provém dos estudos linguísticos, que consideram os gêneros como práticas sociais na perspectiva discursiva da linguagem e a partir de suas contribuições para o estudo da língua, que se fundamentam em orientações "enraizadas em diferentes releituras da herança bakhtiniana" (ROJO, 2005, p. 185), recorrendo a um conjunto de autores como Schneuwly e Dolz (1999), Marcuschi (2008), Geraldi (2006) e Antunes (2003), entre outros.

Esta pesquisa caracteriza-se como do tipo etnográfico, por permitir que sejam conhecidas as situações mais aproximadas do real, considerando o contexto social que, segundo Telles (2002), focaliza as relações entre pessoas (professores, alunos de uma sala de aula, pais, funcionários e administradores de uma escola) dentro de um contexto social (escola, comunidade, família). Tomando a escola como contexto específico, o estudo de campo empreendido foi identificado com a etnografia educacional, que, para Lüdke e André, refere-se à pesquisa em um ambiente educacional, a qual "não deve se restringir ao que se passa no âmbito da escola, mas sim relacionar o que é apreendido dentro e fora da escola" (1986, p. 14).

Este trabalho está organizado de modo a apresentar um pouco do contexto sócio-histórico de Timor-Leste, suas políticas educacionais e linguísticas e a história do desenvolvimento da educação escolar desde o período da colonização portuguesa, passando pelo domínio indonésio, de modo a explicitar o ensino da língua portuguesa em Timor-Leste desde esses períodos até os dias atuais. A seguir, colocamos em discussão como se constitui o ensino na língua portuguesa. Faremos, também, breve incursão aos pressupostos teóricos que fundamentam nossos estudos sobre língua, linguagem e gêneros discursivos, com foco no ensino-aprendizagem da língua portuguesa em Timor-Leste. Por fim, damos destaque à análise, que perscruta a concepção de gêneros na prática pedagógica, correlacionando-a, na medida do possível, com os pressupostos teóricos que fundamentam este trabalho, bem como com os documentos oficiais daquele país. Como desdobramentos 
deste trabalho, nossos resultados apontam para a necessidade de maiores investimentos na formação de professores, com o propósito de levar a uma reflexão sobre prática pedagógica no trabalho com GDs, sobretudo no que se refere às práticas de linguagem, como a leitura e a produção de textos.

\section{Contexto Sócio-HistóRico - LínguA PORTUGUeSA OFICIAL}

Timor-Leste está situado no sudeste da Ásia. Faz fronteira com a Indonésia (parte oeste da ilha) e com a Austrália. O país foi colonizado pelos portugueses por mais de quatro séculos (1511 a 1975). Durante esse período, com a presença dos jesuítas e a fundação de escolas e, posteriormente, com o investimento do governo português na educação, a língua portuguesa foi sendo introduzida.

Em 28 de novembro de 1975, foi declarada a independência do Timor. Porém, o território foi invadido nove dias depois, em sete de dezembro, pela Indonésia, que anexou Timor-Leste ao seu território. Após a invasão indonésia, o país viveu quase vinte e cinco anos de ocupação. Nesse período, além do domínio político, econômico e cultural impingido por aquele país, também ocorreu um domínio linguístico, que propagou o bahasa indonésio e proibiu o uso da língua portuguesa.

Em 2002, o arquipélago foi reconhecido mundialmente e legitimado pelas Nações Unidas como país independente. Foi promulgada a Constituição da República Democrática de Timor-Leste (RDTL), em 22 de março de 2002. A língua portuguesa passou a ter status de língua oficial, ao lado da língua tétum, conforme artigo $13^{\circ}$, parágrafo 1 , que diz: "O Tétum e o Português são as línguas oficiais da República Democrática de Timor-Leste”. Além disso, duas outras línguas são previstas na constituição para serem utilizadas como língua de trabalho: a língua inglesa e o bahasa indonésio.

Apesar de ser a língua oficial, a língua portuguesa é falada somente por uma pequena parcela da população leste-timorense e há uma série de fatores que dificultam seu ensino. As dificuldades apresentam múltiplas dimensões (política, educacional, identitária), pois "o português no Timor-Leste é a língua oficial não porque é falada pela maioria do país, ao contrário são atualmente poucos os que falam o português, em qualquer de suas variedades, mas porque é a língua internacional, a língua da diplomacia, e também, a língua da ciência e da educação" (UNIVERSIDADE FEDERAL DE SANTA CATARINA, 2011, p. 53).

Sendo língua de escolarização, o português é "a língua veicular de acesso aos conhecimentos de outras disciplinas, ou seja, aquela em que os alunos têm de compreender, reter e aplicar conceitos das diferentes disci- 
plinas do currículo" (LEIRIA, 2010, p. 12). Porém, parte dos professores não tem conhecimento da língua portuguesa e recorrem a outras línguas para trabalhar, como malaio, indonésio ou inglês, dificultando o aprendizado.

\section{A língua PORTUGUesa EM TIMOR-LEste: históRIA, ENSinO E ASPECTOS LINGUísTICOS}

À época do mercantilismo e das grandes navegações, Portugal começou a se interessar pela posse do arquipélago, no início exclusivamente para o comércio do sândalo, mel e da cera de Timor. A ilha era frequentada por mercadores privados e aventureiros que iam e vinham. Nesse contexto, a língua portuguesa era utilizada como língua de comércio. Juntamente com os interesses comercias, havia também o interesse na ação missionária, que começou em 1516, quando desembarcaram os primeiros missionários católicos, que se fixaram de forma permanente a partir da fundação de um convento dominicano em 1633, iniciando, assim, o processo educacional do Timor-Leste, com fundação de escolas e a introdução da Língua Portuguesa (PINTO, 2010). No entanto, a política linguística da coroa portuguesa era de ensinar a língua portuguesa apenas para os cidadãos timorenses que tinham alguma influência sobre a população, como os régulos, os chefes e as famílias nobres.

Para Thomaz (2002), o fato mais significativo da história cultural de Timor foi a fundação do Colégio de Soibada, pelos jesuítas, em 1898. O colégio católico destinava-se à formação de professores-catequistas que estavam encarregados de, ao mesmo tempo, alfabetizar e dar instruções religiosas às populações rurais. Nesse colégio, estudaram muitos timorenses que ocuparam espaços no funcionalismo público.

O governo da colônia somente começou a preocupar-se com a educação em 1915, quando foi aberta a primeira escola oficial, em Dili, muito embora a igreja já assegurasse o ensino primário e secundário desde os séculos XVII e XVIII, respectivamente. Em 1938, foi criado um colégio Liceu, destruído pelos japoneses durante a II Guerra Mundial (THOMAZ, 2002).

A Língua Portuguesa manteve em Timor o caráter de língua clerical, administrativa e cultural, e teve um papel muito relevante tanto no plano interno, "como cimento da unidade cultural entre as populações da metade oriental da ilha, retalhada por grupos etno-linguísticos", como no plano externo, "como cordão umbilical que articula as culturas locais, em maior ou menor grau ocidentalizadas por uma aculturação quadrissecular, mas de expressão exclusivamente oral" (THOMAZ, 2002, p. 141).

Com a saída do governo português, ocorreu a invasão indonésia, que provocou significativas mudanças na sociedade e na língua oficial do país. Brito e Bastos (2007) observam que, durante o domínio indonésio, 
Timor-Leste sofreu com torturas, assassinatos e trabalho escravo, além de ter ocorrido uma espécie de "destimorização" a partir da imposição do bahasa indonésio como língua administrativa e de ensino, com a minimização do uso do tétum e com a perseguição de falantes de língua portuguesa. No período da ocupação Indonésia (1975-1999), 90\% da população timorense era analfabeta; a Indonésia investiu na educação pública, mas "com baixa eficiência/eficácia no sistema, com elevadas taxas de reprovação e baixa qualidade" (TIMOR-LESTE, 2011a, p. 7).

Após vários conflitos, o país se torna independente em 2002 e, como uma das consequências, a língua portuguesa foi elevada à categoria de língua oficial, juntamente com a língua tétum. Em 2006, o português passou a ser, também, a língua de instrução naquele país. Segundo a Organização das Nações Unidas (2012), no período compreendido entre 1999 a 2002, o sistema de educação e a infraestrutura educacional estavam quase totalmente devastados, com destruição de cerca de $80 \%$ das escolas e com o êxodo em massa dos professores. Começa-se, então, um novo processo educacional e a reintrodução da língua portuguesa no ensino em Timor-Leste.

Em fevereiro de 2000, a United Nations Transitional Administration in East Timor (UNTAET) assume a administração do território e, em parceria com o Conselho Nacional da Resistência Timorense (CNRT) e a Igreja Católica, procura restaurar o setor da educação, reabilitando e reabrindo as escolas, recrutando novos professores e substituindo o currículo indonésio por um currículo voltado aos propósitos da nova nação. A elaboração de um currículo transitório e a reorganização do sistema educativo desenvolveu-se em torno, principalmente, da introdução da língua portuguesa. Segundo o Programa das Nações Unidas para o Desenvolvimento, muitos professores foram considerados aptos a ministrar aulas para o ensino primário, mesmo que não tivessem formação para tal. Para o ensino pré-secundário e secundário, foram recrutados estudantes universitários, bacharéis e licenciados que, em sua maioria, tinham formação em outras áreas; no entanto, esses professores não tinham conhecimento pedagógico (PNUD, 2002).

Com a aprovação da Lei de Bases de Educação-LBE, em outubro de 2008, Lei n. 14/2008 (TIMOR-LESTE, 2008), que estabelece o quadro geral do novo sistema educativo desde a educação pré-escolar ao ensino básico, secundário e ensino superior e determina os princípios orientadores e as regras fundamentais de organização e funcionamento de todo o sistema, foi elaborado e aprovado o Currículo Nacional de Timor-Leste e aprovados os programas curriculares, em conformidade com os objetivos da Lei de Bases da Educação, com elevado grau de exigência científica e pedagógica, de modo a promover a aprendizagem e proficiência das línguas oficiais (FREITAS, 2012, p. 8). 


\subsection{O Ensino de Língua Portuguesa no Secundário}

O ensino da disciplina Português tornou-se obrigatório no sistema como a língua de instrução em novembro de 2006, conforme Decreto-Lei n. 20, que trata da Lei Orgânica do Ministério da Administração Estatal. A ação desencadeada em função desse Decreto-Lei acionou o Plano Estratégico de Desenvolvimento de Timor-Leste 2011-2030, que esclarece haver no país grandes desafios no que se refere à melhoria da qualidade do ensino secundário, tanto com relação ao currículo quanto à carência de fluência dos professores nas línguas oficiais e de instrução. De acordo com esse documento estratégico,

O currículo não é adequado para servir às necessidades de desenvolvimento do País, a gestão dos professores é precária, com uma taxa de professores por aluno muito baixa, e a qualidade do ensino é deficitária, sendo que muitos professores carecem de fluência nas línguas oficiais e de instrução. (TIMOR-LESTE, 2011a, p. 20).

Após a LBE, o governo timorense passou à elaboração de diversos decretos-leis, de forma a reorganizar as estruturas da educação, incluindo a reforma curricular do ensino básico e secundário e a aprovação de um Currículo Nacional de Timor-Leste. Em 2011, foi elaborado o Plano Curricular do Ensino Secundário Geral, conforme Decreto-Lei n. 47/2011. A concepção do programa do currículo proposto para o $12^{\circ}$ ano do ensino secundário geral fundamentou-se nas orientações enunciadas nos seguintes documentos: Currículo Nacional do Ensino; Constituição da República Democrática de Timor-Leste; Lei n. 14/2008 - Lei de Bases da Educação; Plano Curricular do Ensino Secundário Geral (TIMOR-LESTE, 2008) e Quadro de Referência para o Ensino do Português no Estrangeiro (TIMOR-LESTE, 2011b, p. 4).

Segundo o Programa de Português para as Escolas de Ensino Secundário, o português, "não sendo língua materna da maioria dos alunos timorenses, assume um estatuto peculiar em Timor-Leste, especificamente no contexto escolar timorense, constituindo-se como uma das línguas oficiais e de escolarização (a par do Tétum)." (TIMOR-LESTE, 2011b, p. 4). O Programa de Português (PP) para os três anos do ensino secundário busca contribuir para uma formação sólida do aluno, que lhe permita acompanhar ativamente e com sucesso os programas dos restantes das disciplinas do currículo e desenvolver as competências necessárias ao prosseguimento de estudos e à inserção na vida ativa e/ou à melhor perspectiva de desempenho profissional. o programa também busca consolidar a Língua Portuguesa em Timor-Leste, a médio/longo prazo, em harmonia com as restantes línguas do território. 
Ainda de acordo com o Programa, a disciplina de Língua Portuguesa deve constituir-se como "um espaço de reflexão sobre a língua portuguesa e o diálogo entre contextos onde ela é falada, sendo valorizada a sua diversidade na unidade, assim como a pluralidade linguística de Timor-Leste" (TIMOR-LESTE, 2011b, p. 5).

De acordo com Guterres (2011), os professores se sentem inseguros e apresentam bastantes dúvidas na aplicação de conhecimentos nas escolas, pela falta de apoio para o exercício profissional e pela carência de condições mínimas de infraestrutura na realidade escolar. Tudo isso aliado ao fato de que o português, não sendo língua materna, é considerado segunda língua (o que não se efetiva em função de que ela se constitui como língua de aprendizagem e não de aquisição) e se efetiva, por vezes, como uma terceira língua, o que dificulta a aprendizagem nas escolas, barrando uma educação de qualidade.

O PP procura ampliar e diversificar os diferentes domínios da vida social com vista a preparar os alunos para atuarem nos domínios públicos, privados e profissionais. Esse modo de compreender o trabalho pedagógico no ensino de língua é compatível com a teoria dos GDs, a qual opera com as condições de produção em que as práticas de linguagem ocorrem, para, em seguida compreender como a materialidade textual expressa e produz sentidos, pois é aí que se constituem significações. Daí, entendemos que a modelização pedagógica, focada em trabalhos na perspectiva dos GDs, pode contribuir para uma mudança paradigmática no ensino-aprendizagem da língua portuguesa em uma terra onde a diversidade linguística é, no mínimo, se comparada ao Brasil, idiossincrática.

Tanto no Plano Curricular do Ensino Secundário Geral (2010) quanto no PP para o Ensino Secundário (2010) está explícito o trabalho na perspectiva que consideramos ser dos GDs. Deve-se considerar que os gêneros estabelecem uma ponte interessante para o ensino-aprendizagem da língua portuguesa, possibilitando a compreensão da língua em seus diferentes usos no dia a dia. A efetividade desse trabalho, no entanto, concretizar-se-á se o professor fizer de suas práticas pedagógicas um trabalho que se aproxime da perspectiva dos GDs, com o propósito de levar os estudantes a identificar e fazer uso dos propósitos comunicativos e adequar-se à esfera de circulação e da preocupação com o outro, o que requerem os diferentes gêneros previstos para o $12^{\circ}$ ano.

o plano curricular recomenda ações de produção de linguagem sob a perspectiva dos GDs, propondo aos professores de língua portuguesa mudanças em suas práticas e dando orientações teórico-metodológicas para auxiliar o seu fazer pedagógico. Conforme o Plano Curricular do Ensino Secundário Geral do Ministério de Educação de Timor-Leste: 
A prática da escrita desenvolverá nos alunos competências de produção de textos escritos com a intenção de ficcionar, inventar e criar e recriar textos de diferentes géneros (contos, histórias, jogos poéticos), informar, explicar, descrever (notícias, folhetos, biografias), de convencer, argumentar, aconselhar (reclamações, anúncios, folhetos, avisos), de analisar, comentar e apreciar (texto de opinião). (TIMOR-LESTE, 2011b, p. 20).

Assim, a fundamentação teórica que embasa a realização desta pesquisa compreende que a realidade fundamental da língua é a interação verbal (BAKHTIN, 1997), de modo que, em suas práticas sociais, o indivíduo aja, atue sobre o outro, realize ações e construa conhecimento, entendendo a "língua articulada com o social, onde o homem é concebido como sujeito produtor de textos" (SCHUCHTER; BRUNO, 2010, p. 76).

Os conceitos de GD, quando associados à prática pedagógica do professor de língua portuguesa, devem contribuir para criar as condições necessárias ao ensino e proporcionar aos estudantes o acesso ao conhecimento de textos diversos e ao seu uso correlacionado à prática social da linguagem, de modo a fazer com que o professor crie condições para que os estudantes desenvolvam e internalizem práticas de leitura e escrita e para que possam interagir adequadamente nas variadas esferas sociais de atividade humana.

\section{GÊNEROS DISCURSIVOS}

Ressaltamos as contribuições dos estudos dos gêneros ao ensino da língua, e enfatizamos que se apropriar da concepção de GD é fundamental para o professor em sua prática pedagógica. Assim, como estamos focalizando o ensino-aprendizagem de português em uma escola de Timor-Leste em um contexto multilíngue, é preciso estabelecer correlações e apropriações para fornecer instrumentos teóricos relativos ao ensino e à aprendizagem da língua portuguesa no contexto timorense.

A discussão da noção de gênero trazida por Bakhtin compreende que:

A utilização da língua efetua-se em forma de enunciados (orais e escritos) concretos e únicos, que emanam dos integrantes duma ou doutra esfera da atividade humana. o enunciado reflete as condições específicas e as finalidades de cada uma dessas esferas [esferas da atividade humana], não só por seu conteúdo (temático) e por seu estilo verbal, ou seja, pela seleção operada nos recursos da língua - recursos lexicais, fraseológicos e gramaticais -, mas também, e, sobretudo, por sua construção composicional. Estes três elementos (conteúdo temático, estilo e construção composicional) fundem-se indissoluvelmente no todo do enunciado, e todos eles são marcados pela especificidade de uma esfera de comunicação. 
Qualquer enunciado considerado isoladamente é, claro, individual, mas cada esfera de utilização da língua elabora seus tipos relativamente estáveis de enunciados, sendo isso que denominamos gêneros do discurso. (BAKHTIN, 1997, p. 279).

Marcuschi (2008, p. 22), ao definir gênero textual, ${ }^{1}$ explica que "é impossível se comunicar verbalmente a não ser por algum gênero". Tal afirmação associa-se ao que diz Bakhtin (2002) sobre a importância da língua como atividade social, que se materializa junto ao gênero tanto pelo seu conteúdo quando pelo estilo da linguagem.

Para Marcuschi (2008, p.25), é importante perceber que os gêneros não são estruturas pré-determinadas no contexto de sua utilização, mas são:

Formações interativas, multimodalizadas e flexíveis de formação social e de produção de sentidos. Assim, um aspecto importante na análise do gênero é o fato dele não ser estático nem puro. Quando ensinamos a operar com um gênero, ensinamos um modo de atuação sócio-discursiva numa cultura e não um simples modo de produção textual.

Marcuschi revela a face social que em uma atividade de ensino-aprendizagem deve ser explicitada. A perspectiva evidenciada em Marcuschi aproxima suas ideias, em muito, dos postulados bakhtinanos, haja vista um texto não ser uma matéria formalmente acabada, imutável, mas socialmente viva, conformativa às situações de produção em que os sujeitos estão interagindo.

Oliveira (2008) observa que as ideias do Círculo de Bakhtin trouxeram à Linguística Aplicada novas discussões teóricas, contribuindo para "inovações pedagógicas nas áreas de ensino de línguas”. Para Bakhtin (2003, p. 282), há heterogeneidade nos GDs, classificados em primário, a comunicação do cotidiano, e o gênero de discurso secundário, complexo, que surge em "circunstâncias de uma comunicação cultural, mais complexa e relativamente mais evoluída", que envolve assuntos literários, publicitários, científicos, culturais etc.

Entendendo que há uma variedade de gêneros orais e escritos, os quais podem ser utilizados conforme a intencionalidade comunicativa, podemos dizer que a comunicação ocorre por meio dos gêneros e que o falante deve deles se apropriar para se comunicar em toda e qualquer esfera da sociedade, adequando-se à situação de interação sempre que necessário.

1 Há uma distinção terminológica de Bakhtin (1997) para Marcuschi (2008). Este usa a nomenclatura Gêneros Textuais e aquele Gêneros do Discurso. Neste trabalho, não faremos nenhuma problematização acerca disso, pois foge à finalidade desta pesquisa. Assim, optamos por usar o termo gêneros do discurso ou gêneros discursivos. 
Bakhtin (1997, p. 304) ressalta, ainda, que aprender a falar significa aprender a construir gêneros, "porque falamos por enunciados e não por orações isoladas, e menos ainda, é óbvio, por palavras isoladas". Nesse sentido, é na escola que o uso dos gêneros para o ensino-aprendizagem das práticas de linguagem contribui como ferramenta pedagógica substantiva.

Schneuwly e Dolz (2004) defendem que o gênero é um instrumento imprescindível em uma comunicação (falada ou escrita), com uma situação definida pela intenção comunicativa, com local e destinatário determinados. Schneuwly e Dolz (apud SANTOS, 2010) explicam que, para se usar o gênero, "é necessário que o usuário da língua perceba a situação claramente e, dentro deste contexto de produção, que ele use o gênero através da fala ou escrita (agir linguisticamente), que é um instrumento semiótico estabelecendo, assim, a comunicação" (SANTOS, 2010, p. 35). É por meio dos gêneros que as práticas de linguagem se concretizam nas atividades dos estudantes, não distanciando os gêneros das práticas de linguagem, já que eles efetivam a interatividade entres os indivíduos.

\subsection{Práticas de linguagem}

Considerando o que afirma Bakhthin, de que a vontade discursiva dos falantes se realiza na escolha de um gênero do discurso, a partir do qual o homem interage e se comunica (2006, p. 282), é fundamental compreendermos as noções de práticas de linguagem no que se referem aos gêneros.

Schneuwly e Dolz $(1999$, p. 1) desenvolvem a ideia de que o gênero é utilizado como "meio de articulação entre as práticas sociais e os objetos escolares - mais particularmente, no domínio do ensino da produção de textos orais e escritos". Para esses autores, as práticas de linguagem compreendem as "dimensões particulares do funcionamento da linguagem em relação às práticas sociais em geral”. Desse modo, a linguagem exerce a mediação entre essas práticas, em que o sujeito se apropria de significados e deles faz uso em diversas situações, com o propósito da interação comunicativa. Nessa linha, as Orientações Curriculares para o Ensino Médio do Brasil (BRASIL, 2006, p. 37-38) apresentam os eixos organizadores das ações de ensino e de aprendizagem, que contemplam atividades de produção e de recepção de textos. São eles:

Atividades de produção escrita e de leitura textual, gerados nas diferentes esferas de atividades sociais - públicas e privadas; atividades de produção textual (palestras, debates, seminários, teatro, etc.) em eventos de oralidade; atividades de escuta textual (palestras, debates, seminários, etc.) em situação de leitura em voz alta; atividades de retextualização: produção escrita textual a partir 
de outros textos, orais ou escritos, tomados como base ou fonte; atividades de reflexão sobre textos, orais e escritos, produzidos pelo próprio aluno ou não.

Tais eixos não diferem do proposto pelo Plano Curricular do Ensino Secundário Geral de Timor-Leste (2011b), que orienta para o desenvolvimento das competências em línguas pelos alunos do ensino secundário, as quais consistem em:

Compreender enunciados orais produzidos com diferentes intencionalidades, em contextos formais e informais, pertencentes a diferentes gêneros e veiculados em suportes diversos; exprimir oralmente de forma fluente, desbloqueada e autônoma em contextos formais e informais, nos diferentes domínios da vida social e em diferentes gêneros; compreender textos escritos produzidos com diferentes intencionalidades e registros; produzir textos escritos com diferentes intencionalidades e registros, atendendo ao(s) destinatário(s), aos diferentes domínios da vida social e aos suportes utilizados, mobilizando as características de diferentes gêneros textuais e refletir e sistematizar conhecimentos sobre o funcionamento da língua e o modo de estruturação de textos orais e escritos e mobilizar estes conhecimentos em situação de uso. (TIMOR-LESTE, 2010, p. 29)

Tais propostas mostram preocupação em habilitar os estudantes para a interação em diversas situações de uso da língua, utilizando a escrita e a oralidade. Mas, para que o ensino de língua portuguesa se realize, a proposta é que os GDs sejam instrumento de ensino nas aulas de Língua Portuguesa.

Dessa forma, o ensino de língua portuguesa, segundo Geraldi (2006, p. 106), deverá ser centrado em três práticas articuladas: prática de leitura, prática de produção de textos e prática de análise linguística. Essas unidades, de acordo com o autor, não podem estar separadas, pois, para aprender uma língua, o aluno precisa adquirir o conhecimento das habilidades e competências ligadas e promovidas por meio dessas práticas. $\mathrm{O}$ autor acrescenta, ainda, que o professor deve trabalhar a partir do texto, buscando nele informações e estabelecendo relações dialógicas, em que os textos lidos podem produzir novos textos; a partir destes, surgirão outros.

Lopes-Rossi (2011, p. 81), em sua proposta de projetos pedagógicos de leitura e produção de GD, destaca:

Levar os alunos a perceber que a composição do gênero - em todos os seus aspectos verbais e não verbais, nas informações que apresenta ou omite, no destaque que dá a algumas, mais do que a outras - é planejada de acordo com sua função social e seus propósitos comunicativos. 
No momento em que se pensa compreender o processo de produção de textos em sala de aula, surgem as dificuldades por parte dos estudantes. Não raras são as situações em que esse trabalho se dá conforme a tipologia, que se vincula a práticas tradicionais: dissertação, descrição e narração, sem levar em conta as marcas sociais na produção do texto e a correlação com os usos sociais na comunidade em que os GDs se manifestam. Esse processo distanciado não contribui para a formação de um cidadão crítico e participativo, porque acaba, muitas vezes, por não ser significativo. Assim, nas atividades de leitura e produção de textos, devem ser consideradas as características linguísticas, textuais e discursivas de cada um dos gêneros e conteúdos por eles veiculados, justamente com o propósito de compreendê- los na sua totalidade e alcançar os sentidos possíveis.

Para Cristóvão e Nascimento, o domínio dos gêneros se constitui como instrumento que proporciona uma melhor relação com a leitura e a produção de textos, pois, ao utilizar um texto pertencente a um determinado gênero, o leitor poderá "agir com a linguagem de forma mais eficaz, mesmo diante de textos pertencentes a gêneros até então desconhecidos" (2011, p. 43). Lopes-Rossi (2011, p. 72), por sua vez, adverte que a leitura de GDs na escola nem sempre pressupõe a produção escrita, mas que ela implica sempre atividades de leitura, de modo que os alunos se apropriem das características dos gêneros que irão produzir.

Ao escrever um texto, deve-se saber para quem se escreve e observar se o texto está bem articulado, de modo que o interlocutor possa compreendê-lo. Assim, o texto não será apenas um exercício escolar descontextualizado, mecânico, que não estimula ninguém. A relação de interdependência entre os sujeitos que interagem passa por toda a atividade sociocomunicativa que os liga e, assim sendo, a escrita passa a ser interativa, dialógica, dinâmica e negociável, tanto quanto a fala.

Trabalhar com a prática da escrita de forma contextualizada, com a presença de um leitor para que haja interação, pode levar o aluno a estabelecer vínculos comunicativos, e ele passa a estar consciente do que dizer, como dizer e para quem dizer. O professor "não pode, sob nenhum pretexto, insistir na prática de uma escrita escolar sem leitor, sem destinatário, sem referência, portanto, para se decidir sobre o que vai ser escrito" (ANTUNES, 2003, p. 47).

Trabalhar a partir do GD em sala de aula é também trabalhar com a gramática da língua na prática de análise linguística. Para Antunes (2003), é impossível a existência de uma língua sem uma gramática. Contudo, é importante esclarecer a diferença entre regras de gramática e o ensino de nomenclaturas e classificações. As regras, segundo a autora, servem para orientar o uso das unidades da língua. 
A prática de análise linguística deve considerar a linguagem no seu aspecto de enunciado, de unidade constitutiva de um gênero discursivo. Geraldi afirma que o texto deve partir do aluno:

A análise linguística inclui tanto o trabalho sobre as questões tradicionais da gramática quanto questões amplas a propósito do texto, entre as quais vale a pena citar: coesão e coerência internas do texto; adequação do texto aos objetivos pretendidos; análise dos recursos expressivos utilizados (...); organização e inclusão de informações, etc. (GERALDI, 2006, p. 74)

Ao trabalhar a análise linguística, o professor poderá proporcionar aos alunos formas de organização de um texto, seus elementos gramaticais, coesão, coerência e outros aspectos, com o propósito de levar o aluno a obter explicações sobre o uso da língua com vistas à releitura e à reestruturação de seu texto.

Em suma, pensar práticas necessariamente requer trabalhar na perspectiva dos GDs, e é a partir disso que faremos nossa análise com os instrumentos que mapearam a realidade da escola no Timor.

\section{ANÁLISE}

Na escola a que este trabalho está associado, as aulas ocorrem sempre em português e, quando acontece de os alunos sentirem dificuldades com alguma palavra, o professor utiliza o indonésio ou o tétum para dar maiores esclarecimentos.

$O$ professor timorense de uma turma do $12^{\circ}$ ano diz utilizar a língua portuguesa de forma coloquial, objetivando habituar seus alunos com a sonoridade da língua, além de provocar os alunos a se questionarem fazendo uso do português. Tal procedimento, conforme o professor, deve-se ao fato de alguns alunos resistirem ao ensino de língua portuguesa, dando preferência ao indonésio. $O$ professor acredita que posturas como essas podem ocorrer em função de os pais desses alunos terem aprendido na escola o indonésio e, portanto, fazerem uso da língua portuguesa apenas nas interações escolares, uma vez que no contexto familiar utilizam o tétum e/ ou o indonésio, línguas do cotidiano da família timorense.

Quando o trabalho se volta para a leitura, o professor disse que:

Na leitura, se eles não conseguem, não compreendem, tenho que ajudá-los para saber como pronunciar aquelas palavras que para eles são difíceis, e então depois eu tenho que explicar outra vez em tétum ou bahasa indonésio. Eu só explico a palavra, somente para fazer uma compreensão. Os alunos conseguem compreender a aula 
em língua portuguesa. Eu explico sempre em português, mas só de vez em quando. Quando o menino não compreende, quando tem dificuldades com algumas palavras, então tenho que explicar em tétum e, quando não compreendem em tétum, tenho que explicar outra vez em língua indonésia, porque às vezes eles compreendem em língua indonésia e em tétum, mas isso para fazer uma pequena tradução de algumas palavras que eles não compreendem, não é o texto todo. (informação verbal) ${ }^{2}$

A atividade de leitura proposta pelo professor vai de encontro ao que preconizam os conteúdos previstos nas diretrizes para o ensino e o programa de português, visto que não promove leituras com diferentes finalidades, nem desenvolve competências de compreensão do conteúdo e da forma do texto. Todavia, devemos levar em consideração que a língua portuguesa passou a ser língua de instrução apenas a partir de 2006.

Durante nossas observações, foram trabalhados, em sala de aula, diversos textos que, no nosso entender, na maioria, são gêneros escolares. Para Schneuwly e Dolz (1999):

Na sua missão de ensinar os alunos a escrever, a ler e a falar, a escola, forçosamente, sempre trabalhou com os gêneros, pois toda forma de comunicação, portanto também aquela centrada na aprendizagem, cristaliza-se em formas de linguagem específicas. (SCHNEUWLY E DOLZ, 1999, p. 7)

Durante a observação, o professor trabalhou o gênero lenda. Perguntou se algum aluno sabia sobre a lenda do crocodilo, ${ }^{3}$ e obteve resposta positiva - cada um queria dar sua explicação para a história. Foi um momento de descontração, com a participação de todos em sala de aula. Aqui, a nosso ver, parece principiar um processo que estaria na perspectiva do trabalho com o GD. Na Figura 1, apresentamos o texto e a atividade sobre a lenda do crocodilo.

2 Entrevista concedida pelo professor. Entrevistadora: Maria Irone de Andrade. Dili, 2012. (arquivo em mp3).

3 História contada por gerações sobre como surgiu a ilha de Timor-Leste. 
Figura 1 - A lenda do Crocodilo

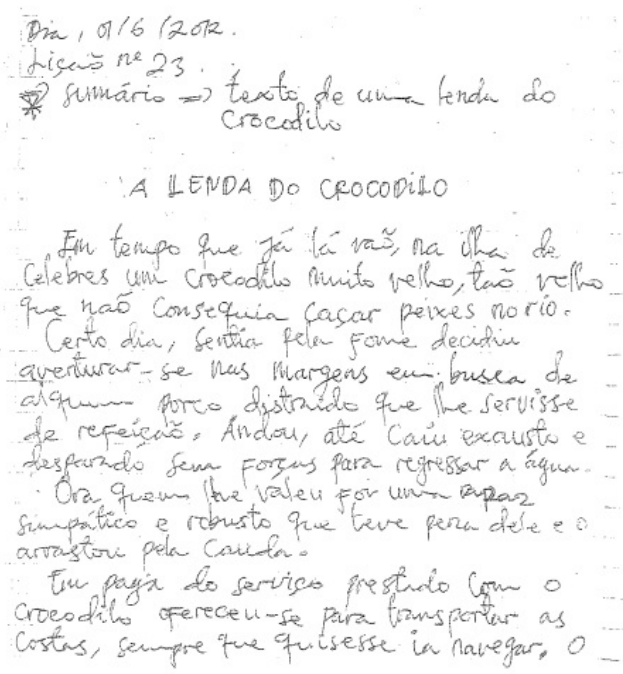

No trabalho sobre interpretação de texto, observamos que o que o professor trata de interpretação pode não ser de fato um exercício interpretativo, embora, para uma língua estrangeira, o encaminhamento dado possa ser importante e significativo naquela situação de interação. Ainda assim, o ideal seria tentar contextualizar a atividade, aproximando-a de uma interação. Vejamos a Figura 2.

Figura 2 - Leitura e interpretação do texto

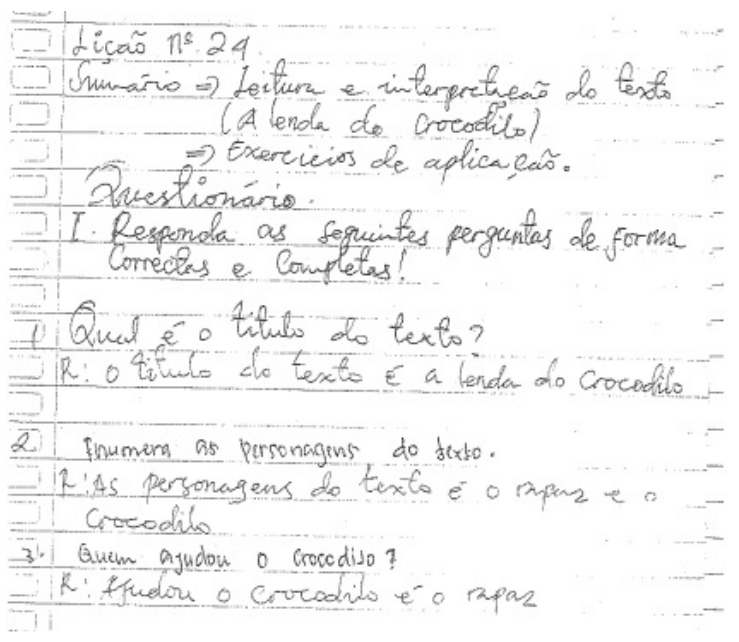


Podemos depreender que o exercício acima, proposto durante a prática pedagógica, visa a apenas extrair informações sobre o texto, ainda esboçando juízo de valor "correcta": não há indagações que proporcionem ir além do explicitado no texto, perscrutando aspectos implícitos importantes acerca da valorização da cultura, de o porquê ser uma lenda ou de outras correlações contextuais relevantes para a formação.

O programa de português para as escolas de ensino secundário de Timor-Leste (2010) propõe atividades com abordagem contextualizada de forma a levar o aluno a relacionar as leituras realizadas com sua experiência pessoal, fazendo-o refletir sobre seu uso no contexto. Entretanto, o modo como as atividades de leitura e produção textual são trabalhados pelo professor, em sala de aula, dificulta a autonomia dos estudantes com os usos da língua em situações comunicativas.

O Plano Curricular do Ensino Secundário Geral (TIMOR-LESTE, 2011b) afirma que uma das finalidades do ensino é desenvolver e consolidar as competências na língua portuguesa. Porém, conforme observação em sala de aula, não percebemos os alunos refletindo sobre a estrutura e o funcionamento da língua e desenvolvendo uma consciência metalinguística. o que percebemos foram alunos tentando responder ao que era solicitado pelo professor, mas sem questionar para além disso. Acreditamos que isso se deve, também, ao fato de os estudantes ainda estarem no processo de "aprender" essa língua, que é deles, mas cujo uso foi proibido por longos anos.

Aliado ao que foi comentado acima, Albuquerque (2011) assevera que falta planejamento linguístico por parte do governo de Timor-Leste, que deveria incentivar a aprendizagem e o uso da língua portuguesa nas diversas situações informais.

Com base em algumas observações em sala de aula, pode-se perceber que o professor faz uso de textos variados, como fábulas, contos, poemas, reportagem (a eleição para presidente) e crônicas, objetivando preparar os alunos para a compreensão do gênero trabalhado, dando sentido e significado ao texto, além de desenvolver a pronúncia, já que a língua portuguesa não é a língua do cotidiano para a maioria dos alunos de Timor-Leste mas deve ser aprendida, em função das orientações legais, como língua oficial do país.

Enquanto o professor focaliza a prática pedagógica nas práticas de oralidade, leitura e significação de palavras, a aula é interativa; quando passa às perguntas, à interpretação de texto (segundo o professor pelo menos) e ao funcionamento da linguagem, os alunos não têm mais interesse. Isso talvez ocorra por ser uma prática baseada apenas na tradição gramatical, cuja ênfase se dá sobre a parte estrutural, que não proporciona a participação dos estudantes quanto ao diálogo. 
Mesmo quando o texto aproxima o contexto da leitura da realidade dos alunos, percebemos que a atividade acaba se voltando para o cumprimento de tarefas didáticas, por vezes limitando-se à interpretação de texto (interpretar as ideias do autor) ou à prática de responder exercícios.

O Programa de Português de Timor-Leste (2010) enfatiza que os alunos do ensino secundário devem desenvolver um conjunto de competências, entre elas: compreender textos escritos produzidos com diferentes intencionalidades e registros, referentes aos diferentes domínios da vida social e em diferentes gêneros. Vemos mais uma vez que o professor, na prática, não desenvolve seu trabalho de acordo com as propostas apresentadas pelos documentos oficiais do Ministério da Educação de Timor. Mesmo esse professor tendo sua formação em língua portuguesa, ele não consegue desenvolver um trabalho voltado à compreensão do objetivo do texto, de quem o produziu ou a quem se destina.

Percebemos que, na prática de leitura, o professor, em geral, desenvolve um trabalho visando à interpretação direcionada e/ou ao cumprimento de tarefas didáticas, não levando os alunos ao gosto pela leitura. Em poucos momentos, o professor privilegiou a construção de sentido do texto, dando espaço para a discussão. Quando da interpretação do texto, verificamos que há pouca ação interativa e significativa: os objetivos didáticos são descontextualizados, sem direcionar para uma formação significativa dos alunos. No trabalho com a produção escrita, percebemos poucas contextualizações das atividades. Acreditamos que tal procedimento deve-se ao fato de o professor repetir a prática tradicional, em que o texto é produzido para ser lido e corrigido pelo professor.

Pelo processo de observação, entendemos que há, ainda, a necessidade de melhor compreensão da diferença entre gêneros e tipos de textos, pois, nas práticas de ensino-aprendizagem, o professor utiliza textos distintos, trabalha objetivando a comunicação, mas falta ainda formação para compreender o trabalho com GD de modo a transformar sua prática pedagógica com vistas a contribuir para a formação de estudantes em cidadãos críticos, que possam dialogar em diferentes situações do cotidiano.

Durante o processo de ensino-aprendizagem, o professor deve desenvolver sua prática conforme o que está previsto nos documentos oficiais, quais sejam: a Lei de Base da Educação, as Diretrizes Curriculares, o Plano Curricular do Ensino Secundário em Timor-Leste e o Programa de Português para o ensino secundário. Esses documentos dão suporte para todos que trabalham na área de educação e constituem referência orientadora para o trabalho em sala de aula, facilitando o desenvolvimento de um ensino de qualidade. 


\section{Algumas considerações}

Considerando as dificuldades enfrentadas pelo professor - como, por exemplo, grande quantidade de alunos na sala de aula, falta de recursos para auxiliar no trabalho com a leitura e a produção textual e as limitações e a falta de informação quanto aos procedimentos adotados nos referidos documentos -, é preciso ressaltar a ausência de maiores investimentos na formação dos professores de língua portuguesa, em especial porque essa é a língua de instrução nesse país. Na prática, o professor privilegia características estruturais da língua, sem dimensionar a ação sociocomunicativa da linguagem, partindo de uma concepção tradicional, o que pode comprometer o êxito do ensino-aprendizagem da língua portuguesa por parte dos estudantes.

Quando observamos a prática do professor e olhamos para o plano curricular, percebemos uma discrepância, pois o plano apresenta uma vinculação teórica focada nas práticas de linguagem com os gêneros. Entretanto, na prática do professor, não observamos isso, o que mostra que quem elaborou esses documentos deveria ter maior conhecimento da realidade sócio-histórica e cultural dos professores timorenses. Além do mais, não podemos esquecer que apenas em 2006 essa língua passou a ser a língua de escolarização.

Identificamos nas práticas do professor grande esforço em ensinar o português, porém, como falamos anteriormente, falta motivação, incentivo e formação para que o professor adquira conhecimentos no trabalho com gêneros, compreendendo-os como inseridos em práticas sociais, objetivando melhorar e ampliar sua capacidade de desenvolver e reconhecer as especificidades dos gêneros e colocá-los em circulação para os estudantes.

Percebemos que o professor tem pouco conhecimento conceitual sobre o que seja língua, linguagem e gêneros discursivos. As concepções do professor apresentadas neste trabalho sobre GD, na prática, não são evidenciadas: não há um enfoque interativo, pelo menos não de um modo sistemático, nas atividades propostas pelo professor.

Durante nossa pesquisa, entendemos que tanto o professor quanto os alunos têm pouco conhecimento da língua portuguesa, o que dificulta o poder de sintetizar a informação recebida e aproveitar as ideias essenciais. O professor investigado utiliza do recurso da leitura silenciosa ou solicita aos estudantes para fazerem leitura em voz alta de um poema ou um texto literário, sem dar atenção para o entendimento do que se está lendo, o que aponta, enquanto evidência, para a necessidade de políticas voltadas para a formação do professor, para que ele possa obter subsídios para melhores práticas em sala de aula.

Há de se pensar quais interferências poderão ser feitas pela Secretaria de Educação de Timor-Leste para a atualização e a formação 
dos professores em favor da melhoria da qualidade do ensino em língua portuguesa. A elaboração do plano de ensino deve se adequar às propostas curriculares; elas também deverão ser viabilizadas pela instituição para que os professores possam conhecer e apropriar-se do trabalho com GD, para que a utilização desse recurso nas aulas de português proporcione aos estudantes a compreensão do que vai ser lido, o entendimento das posições discursivas e ideológicas presentes no texto e a percepção do diálogo de um texto com os outros.

É necessário mais investimento na formação dos professores de português, visando à melhoria da qualidade de ensino dessa língua em Timor-Leste. Tal formação deve ter também um olhar para a cultura, para a organização social e para as diversas línguas que compõem o universo timorense. $O$ ensino da língua portuguesa, nesse contexto, pressupõe estratégias que visam a fazer com que os professores possam minimizar as dificuldades de leitura e escrita em língua portuguesa e desenvolver habilidades para uma melhor compreensão dessa diversidade linguístico-cultural, para que os alunos possam ampliar o senso crítico e a capacidade de agir sobre os textos de diversos GD.

Trabalhar com GDs diversos (propaganda, filme, músicas etc.) promove, por parte dos professores, o ensino-aprendizagem de seus alunos, de modo que as práticas no entorno desses gêneros, tanto a leitura quanto a escrita, podem conduzi-los a entrarem em contato com modos diferentes de ver o mundo, para que eles sejam capazes de conhecer a língua nas suas diversas formas, do cotidiano a gêneros mais complexos, possibilitando assim a produção e a compreensão de textos em situações reais de uso.

São muitos os desafios em relação ao ensino de língua portuguesa no Timor-Leste, porém acreditamos que, com formação contínua, os professores poderão mudar essa realidade e contribuir para um trabalho com o gênero pautado pelo desenvolvimento da linguagem a partir de momentos que privilegiem a interação.

\section{REFERÊNCIAS}

ALBUQUERQUE, Davi Borges. Português de Timor Leste: contribuições para o estudo de uma variedade emergente. PAPIA: Revista Brasileira de Estudos Crioulos e Similares, São Paulo, n. 21, p. 65-82, 2011. Disponível em: < http://abecs.net/ojs/index.php/papia/article/ view/102/335>. Acesso em: 1 nov. 2012.

ANTUNES, Irandé. Aula de Português: Encontro \& Interação. 2. ed. São Paulo: Parábola Editorial, 2003.

BAKHTIN, Mikhail. Marxismo e filosofia da linguagem. 12. ed. São Paulo: HUCITEC, 2002. Estética da criação verbal. 2. ed. São Paulo: Martins Fontes, 1997. 
BRASIL. Ministério da Educação. Linguagens, códigos e suas tecnologias. Orientações Curriculares para o Ensino Médio. Brasília: Secretaria de Educação Básica, 2006. vol. 1.

BRITO, Regina H. P. de; BASTOS, Neusa Maria O. B. "Hello, mister", "Obrigadu barak" e "boa tarde": desafios da expressão lingüística em Timor-Leste. Revista ACOALFAplp: Acolhendo a Alfabetização nos Países de Língua portuguesa, São Paulo, ano 2, n. 3, 2007. Disponível em: $<$ http://www.acoalfaplp.org>. Acesso em: 2 nov. 2012.

COSTA, Luís. O Tétum, factor de identidade nacional, in Timor Lorosa'e. Revista de Letras e Cultura Lusófonas, Lisboa, n. 14, p. 59-64, 2010.

CRISTOVÃO, V. L. L; NASCIMENTO, E. L. Gêneros textuais e ensino: contribuições do interacionismo sócio-discursivo. In: KARWOSKI, Acir Mário et al. (Orgs). Gêneros textuais: reflexões e ensino. Rio de Janeiro: Lucerna, 2011.

FREITAS, João Câncio. Reforma Legislativa e Politicas Educativas do IV Governo Constitucional (2007-2012). Dili, 2 de julho de 2012. Palestra proferida aos alunos mestrandos do Instituto de Formação de Professores e Profissionais da Educação (INFORDEPE).

GERALDI, José Wanderley (org.). O Texto na Sala de Aula. São Paulo: Ática, 2006.

GUTERRES, M. F. L. Choque de realidades dos professores principiantes em Díli (Timor-Leste) Um estudo. 121 f. Dissertação - Mestrado em Ciências da Educação, Universidade de Lisboa, Lisboa, 2011.

LEIRIA, Isabel et al..Orientações Programáticas de Português Língua Não Materna (PLNM) Ensino Secundário. Dili: Ministério da Educação/Direcção-Geral de Inovação e Desenvolvimento Curricular (DGIDC), 2010.

LOPES-ROSSI, M. A. G. Gêneros Discursivos no Ensino de Leitura e Produção de Textos. In: KARWOSKI, A. M.; GAYDECZKA, B.; BRITO, K. S. (Orgs.). Gêneros textuais: reflexões e ensino. 4. ed. São Paulo: Parábola Editorial, 2011.

LÜDKE, Menga; ANDRÉ, Marli E. D. A. Pesquisa em educação: abordagens qualitativas. São Paulo: EPU, 1986.

MARCUSCHI, L. A. Produção textual, análise de gêneros e compreensão. São Paulo: Parábola Editorial, 2008.

PINTO, Filomena da Imaculada Conceição. A percepção da língua portuguesa por estudantes timorenses do ensino superior Português. 83 f. Dissertação de Mestrado (Ciências da Educação) - Faculdade de Ciências Sociais e Humanas, Universidade Nova de Lisboa, Lisboa, 2010.

SANTOS, R. M. A. S. dos S. Os Gêneros textuais como ferramenta didática para o ensino da linguagem. 115 f. Dissertação (Mestrado em Ciências da Linguagem) - Universidade Católica de Pernambuco, Recife, 2010.

SCHNEUWLY, Bernard; DOLZ, Joaquim. Os Gêneros escolares: das práticas de linguagem aos objetos de ensino. Revista Brasileira de Educação, n. 11, mai./jun./jul./ago. 1999, p. 5-16. Disponível em: < http://www.academia.edu/1595337/Os gêneros escolares das praticas de linguagem aos objetos de ensino>. Acesso em: 14 nov. 2012.

SCHUCHTER, L. H.; BRUNO, A. R. Convergências entre Biblioteca Escolar e Laboratório de Informática: o processo de construção de uma pesquisa na abordagem histórico-cultural. In: FREITAS, Maria Teresa de A.; RAMOS, B. S. (orgs.). Fazer pesquisa na abordagem histórico-cultural: metodologias em construção. Juiz de Fora: Ed. UFJF, 2010.

OLIVEIRA, L. C. de. Os gêneros do discurso e novas modalidades de ensino: análise do material didático de espanhol L/E a distância. In: CONGRESSO INTERNACIONAL DE LA ASOCIACIÓN DE LINGÜÍSTICA Y FILOLOGÍA DE AMÉRICA LATINA, 15., 2008, Montevidéu. Anais... Montevidéu: ALFAL, 2008. 
ORGANIZAÇÃO DAS NAÇÕES UNIDAS. Relatório do desenvolvimento humano de Timor-Leste-PNUD. Dili: ONU, 2002. Disponível em: <http://www.tl.undp.org/undp/Publications/UNDP\%20 Timor-Leste\%20publications/NHDR\%202002/NHDR\%20TL_2002_PT.pdf>, Acesso em: 2 nov. 2012.

ROJO, R. H. R. Gêneros do discurso e gêneros textuais: questões teóricas e aplicadas. In: MEURER, J. L.; BONINI, A.; MOTTA-ROTH, D. (orgs.). Gêneros: teorias, métodos, debates. São Paulo: Parábola Editorial, 2005. p. 184-207.

TELLES, João A. É pesquisa é? Ah, não quero, não, bem! Sobre pesquisa acadêmica e sua relação com a prática do professor de línguas. Linguagem \& Ensino, [s. 1.], v. 5, n. 2, p. 91-116, 2002.

THOMAZ, Luiz Felipe Ferreira Reis. Babel Lorosa e o problema Linguístico do Timor-Leste. Lisboa: Cadernos Camões, 2002.

TIMOR-LESTE. Decreto-Lei n. 47/2011, de 18 de outubro de 2011. Plano Curricular do Ensino Secundário Geral do Ministério da Educação de Timor-Leste. Jornal da República Democrática de Timor-Leste, Governo de Timor-Leste, Timor-Leste, 2011a. Disponível em: <http://www. jornal.gov.tl/?mod=artigo\&id=3742>. Acesso em: 2 nov. 2012.

. Lei do Parlamento n. 14/2008, de 17 de outubro de 2008. Lei de Bases da Educação. Jornal da República Democrática de Timor-Leste, Governo de Timor-Leste, Timor-Leste, 2008. Disponível em: <http://www.jornal.gov.tl/?mod=artigo\&id=1453>. Acesso em: 2 nov. 2012.

. Plano de Desenvolvimento Nacional de Timor-Leste. Dili: Comissão do Plano, 2002.

Plano Estratégico de Desenvolvimento 2011-2030. Dili: Governo de Timor-Leste, 2011b. Disponível em: <http://timor-leste.gov.tl/wp-content/uploads/2012/02/Plano Estrategico de Desenvolvimento PT1.pdf>. Acesso em: 2 nov. 2012.

. Ministério da Educação de Timor-leste. Programa wde Português do 10. ano de escolaridade. Dili: Instituto Português de Apoio ao Desenvolvimento; Fundação Calouste Gulbenkian; Universidade de Aveiros, 2010.

UNIVERSIDADE FEDERAL DE SANTA CATARINA. Projeto de acompanhamento do Programa de Qualificação de Docentes e Lingua Portuguesa em Timor-Leste. Florianópolis: UFSC, 2011.

Submetido em: $12 / 07 / 2014$

Aceito em: 16/07/2014 